\title{
Economic Benefit Estimating of Polydimensional Efficiency Measurement Model Implementation
}

\author{
Andrey Aleksandrovich Shishkin, Olga Andreevna Tyugai \\ Organization's Finance Department, Institute of Management, Economy and Finance, Kazan (Volga Region) \\ Federal University, Kazan, Russia \\ Email: and402@yandex.ru
}

Received 3 March 2015; accepted 21 March 2015; published 24 March 2015

Copyright (C) 2015 by authors and Scientific Research Publishing Inc.

This work is licensed under the Creative Commons Attribution International License (CC BY). http://creativecommons.org/licenses/by/4.0/

cC) (7) Open Access

\begin{abstract}
This paper is a revised and expanded version of a paper entitled "The static and dynamic criteria of building an investment asset portfolio" presented at International Conference on Applied Economics (ICOAE, 2014), Chania, 3-5 July 2014 and published at Procedia Economics and Finance, Volume 14, Pages 575-584 (2014) [1]. At the previous research, it showed the significance to go beyond the scope of selecting one or another metric of static efficiency. And the attention was paid to the dynamic efficiency criteria. The ICOAE 2015 research gives brief results of that work, which is only one of applied areas of polydimensional efficiency measurement model (PEMM). Research work on PEMM conceptual and methodical elaboration has been started in the author's dissertation study [2] and continued in the practical activity and materialized in Innovative LLC (limited liability company) creating project. The research is concentrating on the real economic benefit of 3D PEMM (thee criterial PEMM version) implementation. In the first part of ICOAE 2015 empirical study, the dynamic component of 3D PEMM on the industrial level was tested. Next, the company economic profit changes and dynamic-market 3D PEMM components correlation was estimated. Finally, the economic benefit of 3D PEMM functional operationalization in the framework of management systems development was calculated.
\end{abstract}

\section{Keywords}

Investment Portfolio, Shareholder Value, Economic Value Added, Dynamic Performance Criterion, Criterion Value Based Management Efficiency Evaluation Model, 3D Model, Value Based Management, Corporate Governance, Balanced Scorecard 


\section{Introduction}

At the ICOAE 2014 research under the theme for investment portfolio, the necessity of extending the set of traditional efficiency evaluation tools was demonstrated by shifting from the static criterion of performance to the dynamic one (2D version of PEMM). The key objective was to decide whether the dynamic criterion improved the performance of a portfolio, which was initially formed on the basis of the static criterion, EVA metric.

That research did not cover the values of any other factors other than MBR, which would characterize an increase in the company's worth, the firm's capitalization and growth in stock value. In this respect, no additional indices were used in the tested model to ensure that the investment strategy would be easy-to-understand and easy-to-use when based on the proposed theory.

The investment portfolio research was deliberately based on the Russian companies' data. The population included data about companies operating in various sectors of economy and in various markets.

For the purposes of sampling used in the research, we used information from the SPARK (System of Professional Analysis of Markets and Companies) database administered by Interfax Rating Information Agency and the resources of the SPARK rating agency. We reviewed 88 Russian companies covering the period of four years (2009-2012). The sampling amounted to 352 observations.

We conducted the research within the horizon of one, two and three years similarly to the horizons of shortterm, medium-term and long-term strategies for building an investment portfolio.

All statistical calculations were performed with the use of Statistical Package for Social Sciences (SPSS 21.0).

The research covered fifteen companies with the highest EVA index and fifteen companies with the lowest EVA index in total. We also had identified the average means of tested MBR for each subgroup. Within the horizon of one, two or three years, the average means of multiplier characterizing the share price in the open market was higher in the Top-15 Leading Companies group than in Top-15 Lagging Companies group.

Depending on whether there was the equality of variances or not, when analyzing the T-test results, we interpreted the results of one of the two lines of each period. The equality of variances was tested through the Levene's test. The accuracy of the hypothesis on the equality of variances was identified against the Significance value. In our case, it was less than 0.002 in the zero period within the horizon of one and three years of investments, and little more than 0.021 within two years. It meant that the initial hypothesis about significance of EVA could decline with the error probability of $0.2 \%$ and $2.1 \%$ respectively, which was less than the applicable value (5\%). So, the initial hypothesis could be rejected.

The Levene's test results demonstrated that the allocation of tested variable in compared groups had different variances. When selecting one of the two versions of the T-test results for each period, we chose the second line "Equal variances not assumed".

The T-test tested the possibility of the general hypothesis, i.e. "The averages of two groups are equal”. The probability of the hypothesis was tested against the Significance (2-tailed) value. In our case the index did not exceed 0.02 in 2009, 2010 and 2012 but got to 0.028 in 2011. It meant that the initial hypothesis could be accepted at the $5 \%$ level of significance.

Based on the tests had been developed, we could come to the conclusion about the significance of the correlation between economic value added and the market price of the company within all the horizons of the investment portfolio formation process.

Economic value added (EVA) can serve as a rather efficient tool of building an investment portfolio and developing an efficient investment strategy under the emerging market conditions with the period of 1 - 3 years.

Most of research activities focused on an investment portfolio development and selecting an indicator with the best forecasting power would end up exactly at this stage.

Then it was tried to improve the quality of the investment portfolio formed at the first stage using the dynamic performance criterion.

Based on the fact of compliance/noncompliance with standard correlations between growth rates of the companies' internal metrics, the dynamic index values of originally reviewed thirty companies were calculated for the year of 2009.

As the calculation structure of the dynamic performance indicator is derived from statistic characteristics included into the algorithm of its calculation, we have made a secondary sampling based on the dynamic criterion and grouped following the above method. By separating five companies with the lowest dynamic index value in 
the group of leaders by the static indicator (Subgroup 1) and five companies with the highest index dynamic value in the group of the most lagging companies by the statistic indicator (Subgroup 0), a secondary sampling was made out of 20 companies. Dual marking was made to divide the companies into subgroups for potential investments in a more contrasting manner and to simplify the process of statistic analysis.

The above indicators served as the basis for testing the significance of the optimization investment strategy targeted on a qualitative increase in the investment portfolio value. MBR served as an independent variable.

Following the above method, within each investment period, the mean of the market price/book value for the shares of Subgroup 1 were higher than the mean of Subgroup 0.

It was necessary to evaluate the significance of the difference of the means of the two subgroups from the statistical point of view. Statistical calculations were made on the 95 percentage level of the confidence interval. The T-test results related to the correlation between the grouping variable (independent variable-MBR) and the tested variable (dependent variable — dynamic index) had identified the correlation between the indicators under research within all the tested horizons of planning with the probability of error less than 3\% (in 2009-1.4\%, in $2010-2.6 \%$, in $2011-2.8 \%$, in $2012-1.3 \%$ ), which was lower than the acceptable level of $5 \%$.

Subgroups based on the dynamic index showed higher average growth of the portfolio market price. The empiric research performed allows indicating economic efficiency. Results indicates the lightly higher probability of error of the optimization strategy based on 2D PEEM version if compared to that formed by a static criterion. The circumstances are a logical display of the correlation between the expected return and the risk accepted by the investor. In addition, probabilistic risk assessment value in the case of the dynamic criterion stays within the acceptable limit 5 percentage.

ICOAE 2014's first part results generally confirm the illustrative power of the economic value added in emerging economies, which has already been identified [3]. The data acquired indicate the availability of the economic value added significance in post-crisis periods as well. It is necessary to realize that economic value added, which has retained its quantitative significance of its impact on creating the shareholder value even in the post-crisis period, remains a static index of the company's performance only. ICOAE 2014's second part results allow concluding that use of only the static performance criterion limits investor's opportunities of the portfolio's further optimization and excludes the acceptance of additional risk premium on excepted returns reflecting potential growth of shareholder value.

ICOAE 2015 report follows from ICOAE 2014 within conclusion about static criterion's restrictions.

\section{Brief History}

The subject of ICOAE 2015 research is 3D PEMM version implementation in the framework of value based management approach to corporate governance. General concept of PEMM and its 2D version testing on industrial level of Russian sample up to 2009 year are presented in dissertation study. Figure 1 shows the scientific and practical formation of PEMM through three activities.

PEMM is fundamentally different from traditional models of performance evaluation as it allows evaluating the effectiveness in several measures, not metrics or factors.

PEMM is:

1) Easy to understand and interpret the findings;

2) Based on serious theoretical basis of "Value Based Management”, “Total Quality Management” and other world-famous concepts;

3) Universal and equally suitable for all industries;

4) Developed at the junction of the soviet management systems development school and modern management achievements;

5) Take into account the provisions of new international codes of corporate governance and other compilations of the best practices and recommendations of international and professional institutions.

There are several advantages of PEMM:

1) Digital format of the visualization;

2) Reporting character of calculation, including intra-annual periods;

3) Based on a simple economic;

4) Does not change the performance metrics calculating algorithms within the budget or contracts;

5) Adapted for benchmarking; 
since 2004 within the framework of scientific - investigators activities:

\begin{tabular}{|c|c|}
\hline $\begin{array}{l}2004-2006 \text { within the writing } \\
\text { naster's thesis "Evaluation of the } \\
\text { effectiveness of value management; }\end{array}$ & since 2005 within practices: \\
\hline $\begin{array}{l}2004-2011 \text { within writing the } \\
\text { dissertation"Effectiveness evaluation } \\
\text { of an industrial enterprise value based } \\
\text { management " Defenced in } 20.06 .2011 \\
\text { at Saint Petersburg State University of } \\
\text { Economics and Finance; } \\
\text { since } 2011 \text { within the current } \\
\text { research activities (Shishkin A., Tyugai } \\
\text { O. The static and dynamic criteria of } \\
\text { building an investment asset, accepted } \\
\text { for publishing by Elsevier at Reading } \\
\text { book Procedia Economics and Finance } \\
14 \text { ( } 2014 \text { ) } 575 \text { - } 584 \text { of International } \\
\text { Conference on Applied Economics } \\
\text { (ICOAE 2014) provided Technological } \\
\text { institute of western Macedonia, } \\
\text { Greece, 2014. }\end{array}$ & $\begin{array}{l}\text { - since } 2005 \text { within the work as director at } \\
\text { the boards of such companies as JSC } \\
\text { "Kazan agricultural", JSC "IntechBank", } \\
\text { JSC "Radiotehbank", JSC "KZGA-West", } \\
\text { JSC "Aromat", JSC "Adonis", JSC "House of } \\
\text { Tatar cuisine", JSC "GiproVTI", JSC IC } \\
\text { "TatInk", JSC "AIKB"Tatfondbank"; } \\
\text { - } 2006 \text { - } 2014 \text { in the framework of JSC } \\
\text { "Tatfondbank" President adviser post; } \\
\text { - since } 2006 \text { in the framework of } \\
\text { "Perspective" company CEO post; } \\
\text { - since } 2009 \text { in the framework of } \\
\text { Department of Finance organizations } \\
\text { Institute of Management, Economics and } \\
\text { Finance of the Kazan Federal University } \\
\text { lecturer post; } \text { - since } 2014 \text { in the framework of "Kazan } \\
\text { Federal University Research Institute of } \\
\text { organization managment systems } \\
\text { projection" innovative enterprise creating } \\
\text { project. }\end{array}$ \\
\hline
\end{tabular}

since 2014 within the framework of social activities

- since 2014 in the framework of social activities in the regional and national associations of independent directors; - since 2014 at the Committee of the Federal Property Agency "Bankruptcy and Insolvency warning of state owned organizations";

- since 2015 in the framework of Republic of Tatarstan models Passport formation process under the auspices of the Ministry of economy.

Figure 1. Brief history of PEM model formation.

6) Account not only the internal environment of the company, but also the external conditions;

7) Inextricably linked with the strategic drivers of the company value and reflected the standard model of the company;

8) Continuous improvement methodology based on practical experience and statistical calculations.

The final composition of PEMM components depends on a number of objective and subjective factors.

Up to now practical activities and interviews with companies executives allow identifying 7 PEMM components.

Brief characteristic of PEMM versions that are already reproduced in methods and ready for replication are:

- 2D or 2.0 model — two-factor model based on static and dynamic criteria (2.0 method was developed within the framework of the dissertation research);

- 3D or 3.0 model - three-measure model based on static, dynamic and market components (3.0 method was endorsed by Top-50 Russian Bank Board of Directors (included representatives from PricewaterhouseCoopers, BDO, FBK and KFU) 19 February 2013 within the framework of executive management compensations.

\section{The Object of Research}

Within ICOAE 2015 empiric research, there are 2 parts:

1) Industrial level: 2.0 method or 2D PEMM dynamic component on the industrial level of Russia sample.

Developed etalon range of industrial metric's growth rates (1) means that profit should grow faster than any other range metric.

$$
\text { profit }>\text { market size }>\text { production }>\text { average salary }>\text { labour costs }>\text { employees number }>\text { total costs }
$$

Outcome dynamic efficiency indexes are compared with industrial economic value by correlation coefficient. All term and values are identical to Euromonitor vocabulary and methodology.

ICOAE 2015 research tries to formulate general hypothesis for further more complex research.

2) Company level: 3.0 method or PEMM static, dynamic and market components (3D PEMM). 


\section{Methodology}

In the case, the company used economic profit approach and 3.0 method with market index. Market index is based on an assessment of strategic objectives achievement with regard to the influence of external factors (market environment). Static index calculation is based on clear implementation targets.

The indicators included in the 3.0 method calculation are

- static index: assets, operating profit before provisions, loans to individuals, SME Loans, level of credit risk, fee and commission income, overhead;

- market index: assets, loans to individuals;

- dynamic index:

profit before taxes $>$ operating profit before provisioning $>$ commission income $>$ total revenues

$>$ operating assets $>$ equity $>$ salary costs $>$ employee number $>$ overhead costs

Dynamic component operates by growth, not by values [4]. Therefore, even if the performance range of etalon ratios repeats mathematical factors of the economic profit deterministic model, this does not affect the conclusions.

Other components also do not reproduce in calculating the deterministic algorithm of economic profit. Moreover, each index is calculated by dividing the planned values by the actual. At the same time, the correlation is considered by absolute value of economic profit, and not by its growth, it also excludes the impact of repetition.

For economic value added calculation were used Russian accounting standards for the period from 2006 to 2014. The invested capital was defined as the sum of the averages of own and borrowed capital of the company in the reporting year. This is because the cost of borrowing capital of the Bank was determined by calculating through accrued in the reporting period interest expense for each funding source. To assess the value of the Bank's equity used the CAPM model (Capital Asset Pricing Model), the original data was the results of a study published on the website http://www.damodaran.com. We use EBIT, NOPAT instead, because we think that this metric is more suitable for Russian accounting specific and allows negotiating social responsibility effect.

The Banks equity capital was determined as the sum of the sources of own funds. Sources of borrowed capital for economic profit calculating purpose were defined by authors as satisfying at least one of the following conditions: target resources on a long term basis, in case of bankruptcy of the credit institution requirements for the loan are satisfied after the claims of all other creditors satisfaction, the funds raised on the condition of impossibility of early return without approval of the regulator.

We used own and Frakers adjustments to economic value added calculation, especially:

- Adjustments associated with loan loss reserves when a bank has to write off a portion of each loan as soon as it makes. Bank increase its loan loss reserve (reported on its balance sheet) with an equal amount expensed as provision for loan losses (reported on its income statement). This practice distorts the performance measurement of the bank for a given period since the provision for loan losses impacts its net income for that period, even though any potential losses on loans could occur well into the future. Accordingly, to reflect current period losses rather than anticipated future losses, a bank's EBIT is calculated using actual net charge offs for the period rather than its provision for loan [4];

- To assess the tax consequences of temporary differences in the valuation of balance sheet assets and liabilities recognised in the balance sheet deferred tax liabilities (deferred tax liability) and assets (deferred tax asset). However, neither the deferred tax asset or deferred tax liability inherently are no monetary investment or obligations. Therefore, when economic value calculating net deferred tax assets (the difference between deferred tax assets and deferred tax liabilities) are deducted from the capital base. There are no other significant adjustments.

The choice of the adjustments that were made based on their importance and relevance to the research object and an industry.

In the dynamic component or 2.0 method issue, we use Euromonitor database, which is functionally nearly with methodology of core criterion model and comparably with Spark more market oriented. The sample included Russian economy data by Euromonitor industrials separation methodology.

In the case of 3.0 method, we express our gratitude to executives and laborers of JSC for providing management accounting data and for the opportunity of a personal interview that has allowed reproducing in the economic profit and indexes calculations basic concepts of value based management. 


\section{Discussion of Research Results}

\section{0 method}

Industrial level research allows us to formulate several conclusions that will be necessary for further research.

In the framework of industrial level, there are quite high dynamic efficiency indexes. It could be apologised that this is because database contains not industrial, but aggregated of major companies' data. These results confirm the speculation that the dynamic criterion can be digital maturity of company life cycle stage, in addition to analyse tool aspect [5]. In both 2000 (dot-com crisis) and 2008 (world financial crisis) years, we observe comparing higher correlation within the period of 1998-2013. Such results suggest the need of testing crisis predict ability of dynamic criteria.

3.0 method

First of all, we consider it necessary to mention the interpretive limitations of obtained results. Data limitations caused by a small number of observations. This is because the actual model and its components implementation are carried out from 2006 step by step even within board of directors' agendas matters opinion formation. For example, the dynamic component of the model was first implemented in financial modelling in 2009 [6]. As Table 1 and Figure 2 shown, since 2010 there is no economic profit/value added decline. All three components received simultaneous implementation in the executive's salary contracts only in 2013 after year of certain aspects dissections.

In the same year, the first attempts of PEMM implementation was marked in the compensation issue. PEMM was firstly reproduced in the framework of invest project efficiency valuating method, new bank social mortgage product projection and bank product efficiency valuating method in 2006-2007. Based on the PEMM developed a number of interrelated proposals for its functional operationalization. All materials on these questions have been discussing with corporate directors, management and functional stuff in working and official order, which included education pillar. As a result of this system work, public discussion includ managers start to change gradually their approaches, methods, priorities in resource and project planning and even employees and management commands. In general, this complex work can be called a management systems development. Thus, the specificity of the empirical testing of the PEMM implementation effect is the uniqueness of the approach to implementation, which is expressed even in the signalling effect. This conclusion stems from the practice of

Table 1. Results of indexes correlation with the company economic profit.

\begin{tabular}{|c|c|c|c|c|c|c|}
\hline Period & Dynamic index & Market index & Static index & Integral index & $\begin{array}{l}\text { Integral index with } \\
\text { suspensive } \\
\text { dynamic index }\end{array}$ & $\begin{array}{c}\text { Economic } \\
\text { profit } \\
\text { (EBIT based) }\end{array}$ \\
\hline 2014 & $60.00 \%$ & $91.77 \%$ & $92.94 \%$ & 88.92 & 85.92 & $4,277,754$ \\
\hline 2013 & $57.78 \%$ & $87.74 \%$ & $94.81 \%$ & 85.04 & 53.17 & 717,524 \\
\hline 2012 & $84.44 \%$ & $77.92 \%$ & $92.06 \%$ & 78.51 & 40.61 & 460,595 \\
\hline 2011 & $44.44 \%$ & $86.80 \%$ & $93.91 \%$ & 82.98 & 68.99 & 375,242 \\
\hline 2010 & $31.11 \%$ & $100.37 \%$ & $107.03 \%$ & 94.14 & 48.59 & $-271,747$ \\
\hline 2009 & $64.44 \%$ & $103.83 \%$ & $92.11 \%$ & 100.28 & 84.65 & $1,672,785$ \\
\hline 2008 & $35.56 \%$ & $98.31 \%$ & $87.42 \%$ & 92.66 & 55.11 & 478,337 \\
\hline 2007 & $80.00 \%$ & $64.50 \%$ & $87.49 \%$ & 65.89 & $\mathrm{X}$ & $-959,159$ \\
\hline 2006 & $44.44 \%$ & $96.25 \%$ & $106.27 \%$ & 91.59 & $\mathrm{X}$ & $-389,580$ \\
\hline Share_1 & 9.00 & 91.00 & 0.00 & 100.00 & $\mathrm{x}$ & $\mathrm{x}$ \\
\hline Share_2 & 9.00 & 91.00 & 0.00 & 100.00 & $\mathrm{x}$ & $\mathrm{x}$ \\
\hline Correlation & 0.79 & 0.31 & -0.22 & 0.361 & $\mathrm{X}$ & $\mathrm{X}$ \\
\hline $\begin{array}{l}\text { Correlation with } \\
\text { suspensive dynamic } \\
\text { index }\end{array}$ & $\mathrm{x}$ & $\mathrm{x}$ & $\mathrm{x}$ & 0.765 & $\mathrm{x}$ & $\mathrm{x}$ \\
\hline $\begin{array}{l}\text { Share for suspensive } \\
\text { dynamic index }\end{array}$ & 80.00 & 19.00 & 1.00 & 100.000 & $\mathrm{x}$ & $\mathrm{x}$ \\
\hline
\end{tabular}



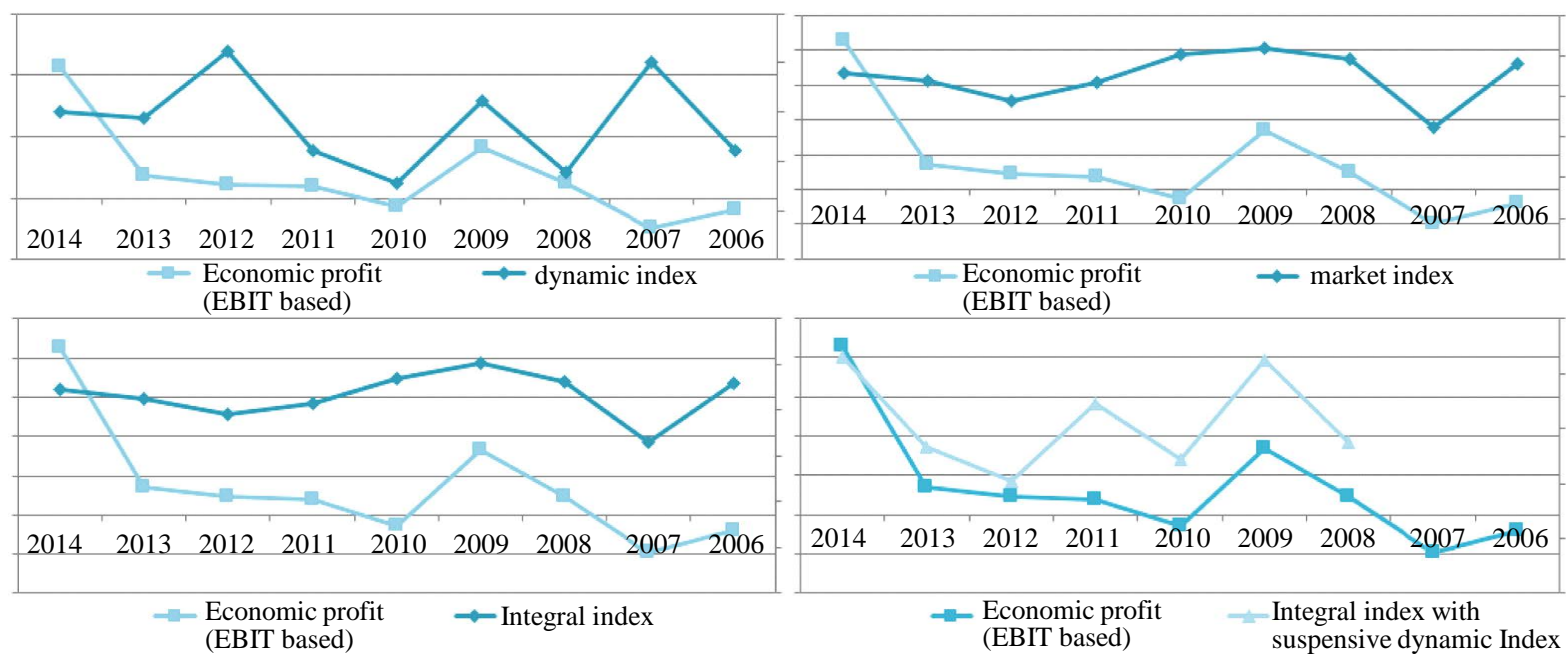

Figure 2. Index correlation with economic profit.

PEMM implementation also in industrial companies [7].

As shown in Table 1 among the three criteria, the best correlation with economic profit/value added shows dynamic index formed with suspensive effect in 2 years. The use of precedent mechanism caused by analytical nature of dynamic economic measurement that evaluates the structural and not situational shifts in (in regard to correlation) share of static index or static criteria tends to zero. Basic selection of model/integral index components (dynamic, market, static) weights in the case of suspensive dynamic index has allowed us to increase the correlation between integral index and economic profit/value added up to 0.765 that much higher than 0.361 in the case of suspensive mechanism absence. With all of these, the company's management accounting economic value added is not used in the state of 2014. That eliminates the predetermination of the outcome.

The obtained results confirm the assumption that the improvement of management systems in orientation on the 3D PEMM yields real benefits in terms of company economic profit/value added growth.

\section{Conclusion}

Content of conclusions and discussion parts of the research is limited because of "know-how commercial confidentiality mode" of PEMM. The research results quantitatively confirm the thesis about the economic effect of PEMM implementation on the company's management functional issues. Economic profit, as previously shown, is the best tool for emerging markets to reflex a company market value. The differences in the correlation of each index with the economic profit suggest that the market and dynamic indexes allow improving the more informative power to the integral one. Thus, their influence would be recognized as significant.

\section{References}

[1] Shishkin, A. and Tyugai, O. (2014) The Static and Dynamic Criteria of Building an Investment Asset Portfolio. Procedia Economics and Finance, 14, 575-584. http://dx.doi.org/10.1016/S2212-5671(14)00740-0

[2] Shishkin, A. (2011) Effectiveness Measurement of Industrial Enterprise Value Creation. Dissertation, Saint-Peterburg State University of Economy, St. Petersburg, 206 p.

[3] Ankudinov, A., Gizatullin, A. and Shishkin, A. (2006) Economic Value Added as a Governance Tool: The Case of Emerging Market, In: Reading Book Addressing the International Conference, Management and Technology in the Global Economy: Nurturing Innovation and National Heritage, Global Business and Technology Association, State University of Management, Moscow, 42-98.

[4] Fraker, G.T. (2006) Using Economic Value Added (EVA) to Measure and Improve Bank Performance. Paper Writing Contest RMA-Arizona Chapter.

[5] Byakov, O.A. (2004) Economic Space: A Process Approach. Kuzbassvuzizdat, 189 p.

[6] Shishkin, A. (2009) Value Based Model of Bank Governing Design. Economic Analysis: Theory and Practice, 25, 42-55.

[7] Shishkin, A. (2010) Dynamic Criterion in Estimating of the Efficiency of Industry Companies Value Creation Process. Vestnik KSFEI, 4, 40-44. 